\title{
Correlates of alcohol withdrawal
}

\author{
Rajmohan Velayudhan
}

\section{Aims}

To study the withdrawal process and its association with clinical and socio-demographic factors.

\section{Methods}

A total of 126 patients, all males admitted to an inpatient de addiction unit in Kerala for treatment were assessed and based on the inclusion criteria 103 patients were included in the study. A semi structured proforma was used to collect socio-demographic data, CIWA- Ar was used to assess severity of withdrawal. Motivation and social support were assessed.

\section{Results}

The severity of withdrawal correlated significantly with the years of dependent use $(p<0.001)$, the amount of alcohol consumed $(p<0.001)$, the external pressure score of motivation scale $(p=0.02)$ and the liver enzyme levels.

\section{Conclusions}

Higher amounts of alcohol consumption, the years of dependent use, treatment on external pressure and liver enzyme abnormalities were associated with severe withdrawal.

SL J Psychiatry 2013; 4 (2): 34-37

\section{Introduction}

Alcohol withdrawal is a clinical syndrome that results when people dependent on alcohol either decrease their alcohol consumption or completely stop drinking. The mechanism of withdrawal are clear, however there is disagreement on the risk, complication, and clinical management of withdrawal (1). The spectrum of alcohol withdrawal symptoms ranges from minor symptoms such as insomnia and tremulousness to severe complications such as withdrawal seizures and delirium tremens (2). Factors like an initial withdrawal score of $\geq 10$ on the Clinical Institute Withdrawal Assessment for Alcohol (CIWA-Ar) scale, a high serum aspartate aminotransferase, or prior participation in two or more alcohol treatment programs were associated with severity of the withdrawal syndrome (3). Other factors that have been associated with severity of withdrawal include quantity of alcohol consumed, number of years of heavy drinking, medical co-morbidity, age, and the role of benzodiazepines (4-6). The present study aims to study the withdrawal process and the clinical and socio-demographic factors affecting it and the role of patient's motivation to undergo treatment and its relation to withdrawal.

\section{Method}

\section{Sample}

The study was conducted in the inpatient de addiction unit of the Department of Psychiatry, of a Private Medical College in Kerala. The sample consisted of consecutive patients admitted to the ward from January 15 th to August 15 th of 2012. Patients meeting the following inclusion criteria were included. The following patients were included in the study based on the basis of the following criteria; (a) Providing informed consent (b) meeting the criteria for alcohol dependence as per ICD-10 (DCR)(7) (c) currently having withdrawal symptoms and having a CIWA-Ar score of $\geq 8$ at the time of admission. The following were exclusion criteria (a) patients who were abstinent and treated detoxified just prior to admission (b) patients treated as outpatients (c) patients who were dependent on substances other than nicotine and caffeine (d) patients with learning disability or any condition other than delirium due to withdrawalwhich made it difficult to obtain informed consent or Obtain necessary information. Ethics Committee approval was obtained prior to conduction of the study.

\section{Assessment}

A semi structured proforma was used to elicit sociodemographic and clinical data from the patients. Alcohol dependence was diagnosed according to The ICD10 (DCR) criteria (7). Clinical Institute Withdrawal Assessment for Alcohol-revised (CIWA-Ar) was used to rate the withdrawal syndrome $(8,9)$. This scale rates ten withdrawal features and takes only a few minutes to administer. The scale was applied at the time of admission and those with a score $\geq 8$ were included in the study. This score indicates need for detoxification and increased risk of severe withdrawal (10). CIWA-Ar scores of $<8$ indicates low risk of seizures and can be managed without specific pharmacotherapy $(11,12)$.

Delirium Rating Scale (DRS) was used to assess delirium. This is a 10 point observer rated scale, which evaluates a variety of delirium symptoms (13). The Texas Christian University- Treatment Motivation Scale was used to assess the treatment motivation of the patient. This is a 29 item self evaluated scale with each item scored from $0-5$. It evaluates factors like problem recognition, desire for help, treatment readiness and external pressures (14). Scale for Measurement of Social Support was used to assess social support (15).

A detailed clinical evaluation was done and investigated with routine investigations including fasting blood sugar, liver and renal function tests were 
done. Ultrasound and other tests were carried out if indicated. Physical co morbidities were confirmed by consultation-liaison with a physician.

Statistical analysis

The data were analysed and results were recorded as means and proportions. Chi-square procedures were done to test association between categorical variables. The strength of the association between two continuous variables was analysed using Pearson's product moment correlation coefficient (Pearson's r). Difference between means was tested with $t$ test. Data analysis was done using SPSS 20.0 for Windows (16).

\section{Results}

A total of 126 patients, all males were admitted for inpatient treatment. Based on the inclusion criteria 103 patients were included in the study. Of the 23 excluded, 15 had a CIWA-Ar score of $<8$, five had been treated with benzodiazepines prior to admission and three patients didn't complete the treatment.

The mean age of the sample was 43.4 years. The majority of the sample $(70.9 \%)$ were of low socio economic status and the rest were of middle socioeconomic status $(29.1 \%)$. This is similar to the socio economic pattern of the population which attends the hospital. Eighty eight $(85.4 \%)$ were married, $9(8.7 \%)$ were unmarried; and $6(5.8 \%)$ were divorced or separated. Average age of onset of alcohol use was 18.1 years. The average years of dependence was 16.4 years. The average daily alcohol consumption of the different types of alcohol estimated for the last 30 days using a quantity frequency method was $237.9 \mathrm{~g}$ of ethanol. Of the patients included $66(64.1 \%)$ had undergone detoxification previously. Physical illness was the reason for current admission in 87 patients $(84.5 \%)$.

\begin{tabular}{|c|c|}
\hline Age & 43.4 years \\
\hline $\begin{array}{l}\text { Socio-economic status } \\
\text { Low } \\
\text { Middle }\end{array}$ & $\begin{array}{l}70.9 \% \\
29.1 \% \\
\end{array}$ \\
\hline $\begin{array}{l}\text { Marital status } \\
\text { Married } \\
\text { Single/divorced/separated }\end{array}$ & $\begin{array}{l}85.4 \% \\
14.6 \%\end{array}$ \\
\hline $\begin{array}{l}\text { Reason for admission } \\
\text { Physical illness } \\
\text { For de-addiction }\end{array}$ & $\begin{array}{l}84.5 \% \\
15.5 \% \\
\end{array}$ \\
\hline $\begin{array}{l}\text { Previous detoxification } \\
\text { Yes }\end{array}$ & $64.1 \%$ \\
\hline $\begin{array}{l}\text { Family history of alcoholism } \\
\text { present }\end{array}$ & $74.8 \%$ \\
\hline $\begin{array}{l}\text { Mean daily alcohol } \\
\text { consumption }\end{array}$ & $237.9 \mathrm{~g}$ \\
\hline $\begin{array}{l}\text { Alcoholic liver disease } \\
\text { Delirium tremens } \\
\text { Alcohol withdrawal seizures } \\
\text { CIWA-Ar score(mean) } \\
\text { Delirium rating score (mean) }\end{array}$ & $\begin{array}{l}47.6 \% \\
22.3 \% \\
20.4 \% \\
19.3 \\
23.6\end{array}$ \\
\hline
\end{tabular}

Family history of alcohol use was high. Seventy seven $(74.8 \%)$ had first-degree relatives with history of alcohol use. Family history of suicides was present in 35 $(34.0 \%)$ and mental illness in $22(21.4 \%)$. Laboratory and ultrasound evidence of alcoholic liver disease was present in $49(47.6 \%)$. Of the sample 23 patients presented with delirium $(22.3 \%)$ and 21 patients $(20.4 \%)$ developed withdrawal seizures. (Table 1$)$

The correlation of the CIWA-Ar scores with the different socio demographic factors and clinical factors is given in table 2. Significant correlation was seen with CIWA-Ar scores and years of dependent use $(p<0.001)$, amount of alcohol consumed per day $(\mathrm{p}<0.001)$, external pressure score on the motivation scale $(p=0.02)$, the SGOT level (serum glutamic-oxaloacetic transaminase) $(\mathrm{p}<0.001)$ and the SGPT level(serum glutamic-pyruvic transaminase $)(p=0.004)$. Other factors did not show any significant correlation. (Table 2) Age $(r=-0.54$; $\mathrm{p}=0.83$ ), age of onset of alcohol use, social support, and other motivation scores all showed negative correlation with the severity of withdrawal, but were not significant (Table 2).

There was a significant correlation between the external pressure score in the motivation scale and the severity of withdrawal. Patients with high scores on external pressure scale had lesser degree of motivation and the scores were positively correlated with severity of withdrawal. The scores of other domains of motivation and social support were not significantly correlated with the severity of withdrawal. Treatment readiness, desire for help and problem recognition were negatively correlated with the CIWA-Ar score, but it was not statistically significant. The social support scores were negatively correlated with withdrawal severity.

Correlation of the percentage improvement in CIWAAr scale within the first 48 hours after initiation of

\begin{tabular}{|l|l|l|}
\hline \multicolumn{3}{|c|}{ Table 2 - Factors correlating with severity of withdrawal } \\
& $\begin{array}{l}\text { Pearsons } \\
\text { correlation }\end{array}$ & $\begin{array}{l}\text { Significance } \\
\text { (2 tailed) }\end{array}$ \\
\hline Age & 0.14 & 0.16 \\
\hline Age of onset & -0.08 & 0.43 \\
\hline Years of dependent use & 0.35 & $<0.001^{*}$ \\
\hline Amount of alcohol & 0.63 & $<0.001^{*}$ \\
\hline Social support & -0.05 & 0.73 \\
\hline Problem recognition & -0.15 & 0.14 \\
\hline Desire for help & -0.15 & 0.14 \\
\hline Treatment readiness & -0.07 & 0.48 \\
\hline External pressure & 0.22 & $0.03^{*}$ \\
\hline $\begin{array}{l}\text { SGOT } \\
\text { SGPT }\end{array}$ & 0.35 & $<0.001^{*}$ \\
\hline
\end{tabular}


treatment with the different variables is given in table 3 . This examines the association of these variables with the rate of reduction of the symptoms of withdrawal. The rate of reduction of the score was also correlated with the initial CIWA-Ar score to see if severity of withdrawal had a bearing on the rate of withdrawal. There was a significant correlation between the years of dependent use $(\mathrm{p}=0.04)$, CIWA-Ar admission score $(p<0.001)$, SGOT and SGPT levels $(p<0.001)$ and initial improvement in CIWA-Ar score. The other socio demographic, clinical, social support, and motivational factors did not show a significant correlation. A subsequent linear regression showed that these factors did not contribute significantly to the improvement in CIWA-Ar score and most of the improvement was due to treatment with benzodiazepine).

Age of onset had a significant association with the development of withdrawal seizures, younger patients had higher risk of seizures (Mann Whitney $\mathrm{U}=$ 486.5, $\mathrm{p}=0.02$ ). The duration of dependent use was significantly associated with delirium (Mann Whitney $\mathrm{U}=578, \mathrm{p}=0.07)$. The occurrence of seizures was not significantly associated with the years of dependence (Mann Whitney $U=728, p=0.27$ ). The amount of alcohol consumed was associated with delirium (Mann Whitney $U=279.5, p<0.001)$, but not with withdrawal seizures (Mann Whitney $\mathrm{U}=750.5, \mathrm{p}=0.35$ ).

\section{Discussion}

The study shows that the severity of withdrawal correlated significantly with the years of dependent use, amount of alcohol consumed, external pressure score of motivation scale and the liver enzyme levels. The analysis of the data shows that age has no significant influence on the severity of withdrawal though it shows a negative correlation with the

Table 3 - Factors correlating with initial CIWA-Ar improvement

\begin{tabular}{|l|l|l|}
\hline & $\begin{array}{l}\text { Pearsons } \\
\text { correlation }\end{array}$ & $\begin{array}{l}\text { Significance } \\
\text { (2 tailed) }\end{array}$ \\
\hline Age & 0.17 & $0.08^{*}$ \\
\hline Age of onset & -0.13 & 0.19 \\
\hline Years of dependent use & 0.281 & $0.004^{*}$ \\
\hline Amount of alcohol & 0.17 & 0.09 \\
\hline CIWA-Ar inital score & 0.26 & $0.01^{*}$ \\
\hline Social support & 0.11 & 0.26 \\
\hline Problem recognition & -0.180 & 0.07 \\
\hline Desire for help & -0.01 & 0.89 \\
\hline Treatment readiness & -0.13 & 0.18 \\
\hline External pressure & 0.04 & 0.66 \\
\hline $\begin{array}{l}\text { SGOT } \\
\text { SGPT }\end{array}$ & 0.42 & $<0.001^{*}$ \\
\hline
\end{tabular}

phenomenon of withdrawal. This is in agreement with other studies that found that severity of withdrawal, as measured by CIWA-Ar scores were not associated with age(10). However some studies have shown that elderly alcohol dependent individuals underwent more severe withdrawal and received higher doses of benzodiazepines than younger patients $(17,18)$. These studies included a large number of patients above 60 but the oldest member of our sample was 63 years of age and there were only a few patients above 60 years of age, therefore this observation needs further evaluation (17).

The age of onset did not correlate significantly with the severity of withdrawal but it was significantly associated with the development of withdrawal seizures, younger patients were at higher risk. The duration of dependent use significantly correlated with withdrawal severity and development of delirium This supports previous findings that longer duration of use correlates with severity of withdrawal including the occurrence of seizures (19). This contradicts the finding that long periods of continuous drinking do not influence severe withdrawal (20). It also contradicts the findings reported in another study examining the role of duration of use in severe withdrawal (9). The occurrence of seizures was not significantly associated with the years of dependence

The amount of alcohol consumed daily correlated significantly with severity of withdrawal and was associated with development of delirium but not withdrawal seizures. Some studies have found that severity of withdrawal is correlated with the amount consumed (18). However some studies have reported that there was no significant association (9).

There was a significant correlation between the external pressure score in the motivation scale and the severity of withdrawal. The scores of other domains of motivation and social support were not significantly correlated with the severity of withdrawal. The social support scores were negatively correlated with withdrawal severity. We could not find other studies which support or contradict these observation and further research needs to be done with respect to these factors. Further follow up study to evaluate the role of these factors in long term prognosis is recommended.

Liver enzymes levels were significantly correlated with the severity of withdrawal. This supports an earlier observation that serum AST (SGOT) of $80 \mathrm{U} / \mathrm{L}$ or greater, correlated with severe withdrawal (9).

Initial improvement in CIWA-Ar score were correlated with severity of withdrawal on admission, years of dependent use, and SGOT, SGPT levels. However these variables were not significant in a stepwise linear regression model. We did not find any studies which reported on these factors.

This study though limited by a smaller sample size and limited to a tertiary care setting identified different clinical correlates of alcohol withdrawal. This can help in identifying patients at risk of severe withdrawal. Further it highlights the need for accurate assessment of 
withdrawal with a standardised instrument like CIWA$\mathrm{Ar}$ in order to identify those at high risk which would enable appropriate treatment, and prevent overuse of benzodiazepines.

\section{Declaration of interest \\ None declared}

R.Velayudhan, Associate Professor,

Mes Medical College

Perinthalmanna, Kerala, India

Corresponding author: R.Velayudhan

E mail: rajgiggsmohan@yahoo.com

\section{References}

1. Saitz R. Introduction to alcohol withdrawal. Alcohol Health \& Research World, 22:1, 5-12.

2. Bayard M, McIntyre J, Hill KR, Woodside J Jr. Alcohol withdrawal syndrome, American Family Physician, Mar 15;69(6):1443-50.

3. Kraemer KL, Mayo-Smith MF, Calkins DR. Independent clinical correlates of severe alcohol withdrawal, Substance Abuse, 24:4,197-209.

4. Pristach CA, Smith CM, Whitney RB. Alcohol withdrawal syndromes - prediction from detailed medical and drinking histories, Drug Alcohol Dependence, 11:2177-99.

5. Schuckit MA, Tipp JE, Reich T, Hesselbrock VM, Bucholz KK. The histories of withdrawal convulsions and delirium tremens in 1648 alcohol dependent subjects, Addiction, 90:10,1335-47.

6. Wojnar M, Wasilewski D, Zmigrodzka I, Grobel I. Age-related differences in the course of alcohol withdrawal in hospitalized patients, Alcohol Alcohol, 36:6,577-83.

7. ICD-10 classification of mental and behavioural disorders: Diagnostic Criteria for Research, World Health Organisation.

8. Sullivan JT, Sykora K, Schneiderman J, Naranjo CA, Sellers EM. Assessment of alcohol withdrawal: The Revised Clinical Institute Withdrawal assessment for alcohol Scale (CIWAAr), British Journal of Addiction, 84,175-180.
9. Foy A, March S, Drinkwater V. Use of an objective clinical scale in the assessment and management of alcohol withdrawal in a large general hospital, Alcoholism: Clinical and Experimental Research, 12,360-364.

10. Kraemer K L, Mayo-Smith M F, Calkins, DR. Impact of age on the severity, course, and complications of alcohol withdrawal, Archives of Internal Medicine 157, 2234-2241.

11. Mayo-Smith MF. Pharmacological management of alcohol withdrawal: A meta-analysis and evidencebased practice guideline, Journal of the American Medical Association, 278, 144-151.

12. Saitz R, O'Malley SS. Pharmacotherapies for alcohol abuse: Withdrawal and Treatment, Medical Clinics of North America, 81:4, 881-907.

13. Trzepacz PT, Baker RW, Greenhouse J. A symptom rating scale for delirium, Psychiatry Res, 23:1, 89-97

14. Gerdien H. De Weert-Van Oene, Gerard MS, Cor AJ De Jong, Guus (A) JP Schrijvers. Motivation for Treatment in Substance-Dependent Patients: Psychometric Evaluation of the TCU Motivation for Treatment Scales, European Addiction Research, 8:2-9.

15. Ritu Mehra, Kulhara P, Verma SK. Scale for Measurement of Social Support, Indian Journal of Clinical Psychology, 23:1, 33-39.

16. Statistical Package for the Social Services 15.0 for Windows, SPSS Inc. All rights reserved. SPSS Inc. Headquarters, $233 \mathrm{~S}$. Wacker Drive, 11th floor Chicago, Illinois 60606.

17. Liskow, BI, Rinck, C, Campbell J, DeSouza C. Alcohol withdrawal in the elderly, Journal of Studies on Alcohol 50, 414-421.

18. Foy A., Kay J. Taylor A. The course of alcohol withdrawal in a general hospital, Quarterly Journal of Medicine 90, 253-261.

19. Palmstierna T. A Model for Predicting Alcohol Withdrawal Delirium, Psychiatric Services 52,820-823.

20. Freidman H J. Assessment of physical dependence on and withdrawal from ethanol in animals, Alcohol Tolerance and Dependence, Rigter, H. and Crabbe, J. C. Jr eds, pp. 93-121. 